\title{
Mechanism of parkinsonian neuronal oscillations in the primate basal ganglia: some considerations based on our recent work
}

\author{
Atsushi Nambu ${ }^{1,2 *}$ and Yoshihisa Tachibana ${ }^{1,2}$ \\ ${ }^{1}$ Division of System Neurophysiology, National Institute for Physiological Sciences, Okazaki, Japan \\ ${ }^{2}$ Department of Physiological Sciences, Graduate University for Advanced Studies, Okazaki, Japan
}

\section{Edited by:}

Ahmed A. Moustafa, University of Western Sydney, Australia

\section{Reviewed by:}

Alessandro Stefani, University of Rome, Italy

Reuben R. Shamir, Case Western Reserve University, USA

${ }^{*}$ Correspondence:

Atsushi Nambu, Division of System Neurophysiology, National Institute for Physiological Sciences, 38 Nishigonaka, Myodaiji, Okazaki 444-8585, Japan

e-mail:nambu@nips.ac.jp
Accumulating evidence suggests that abnormal neuronal oscillations in the basal ganglia (BG) contribute to the manifestation of parkinsonian symptoms. In this article, we would like to summarize our recent work on the mechanism underlying abnormal oscillations in the parkinsonian state and discuss its significance in pathophysiology of Parkinson's disease. We recorded neuronal activity in the BG of parkinsonian monkeys treated with 1-methyl-4-phenyl-1,2,3,6-tetrahydropyridine. Systemic administration of L-DOPA alleviated parkinsonian motor signs and decreased abnormal neuronal oscillations $(8-15 \mathrm{~Hz})$ in the internal (GPi) and external (GPe) segments of the globus pallidus and the subthalamic nucleus (STN). Inactivation of the STN by muscimol $\left(G_{A B A}\right.$ receptor agonist) injection also ameliorated parkinsonian signs and suppressed GPi oscillations. The blockade of glutamatergic inputs to the STN by local microinjection of a mixture of 3-(2-carboxypiperazin-4-yl)-propyl-1-phosphonic acid (glutamatergic NMDA receptor antagonist) and 1,2,3,4-tetrahydro-6-nitro-2,3-dioxo-benzo[f]quinoxaline7-sulfonamide (glutamatergic AMPA/kainate receptor antagonist) suppressed neuronal oscillations in the STN. STN oscillations were also attenuated by the blockade of GABAergic neurotransmission from the GPe to the STN by muscimol inactivation of the GPe. These results suggest that cortical glutamatergic inputs to the STN and reciprocal GPe-STN interconnections are both important for the generation and amplification of the oscillatory activity of GPe and STN neurons in the parkinsonian state. The oscillatory activity in the STN is subsequently transmitted to the GPi and may contribute to manifestation of parkinsonian symptoms.

Keywords: Parkinson's disease, neuronal oscillation, globus pallidus, subthalamic nucleus, $\beta$-band, monkey, basal ganglia

\section{INTRODUCTION}

Parkinson's disease (PD) is a neurodegenerative disorder affecting motor and non-motor functions. Motor dysfunction in PD, including akinesia, tremor and rigidity is largely attributed to the progressive loss of dopaminergic (DAergic) neurons in the substantia nigra pars compacta. There are two hypotheses that explain the pathophysiology of PD. The "firing rate model" originally proposed that dopamine (DA) depletion reduces tonic excitation to striatal neurons projecting to the internal segment of the globus pallidus (GPi) (i.e., direct pathway) and tonic inhibition to striatal neurons projecting to the external segment of the globus pallidus (GPe) (indirect pathway) (DeLong, 1990; Mallet et al., 2006). Both of these changes are thought to increase average firing rates of GPi and substantia nigra pars reticulata neurons. This increased activity in the basal ganglia (BG) output nuclei induces decreased activity in thalamic and cortical neurons, resulting in akinesia. However, recent electrophysiological studies using 1-methyl-4-phenyl-1,2,3,6-tetrahydropyridine
(MPTP)-induced PD monkeys have failed to detect an expected increase in GPi activity (Wichmann et al., 1999; Raz et al., 2000; Rivlin-Etzion et al., 2008).

The firing rate model has now been largely supplanted by the "firing pattern model" that emphasizes oscillatory and/or synchronized activity. Oscillatory and/or synchronized activity is frequently observed in the BG of patients with movement disorders and animal models, which may cause the disturbance of information processing in the BG (Bergman et al., 1998). Unit activity and local field potentials recorded from PD animals and patients have shown oscillatory and synchronized activity in the GPe, GPi and subthalamic nucleus (STN; Bergman et al., 1998; Levy et al., 2000; Raz et al., 2000; Brown et al., 2001; Brown, 2007). The frequency bands include the tremor (4-9 Hz) and $\beta(10-30 \mathrm{~Hz})$ bands. The $\beta$-band oscillation may be a primary cause of akinesia, since the treatment of akinesia with drugs effectively suppresses the $\beta$-band oscillation. Recent studies also reported $\beta$-band synchronized activity in STN 
neurons of PD patients (Moshel et al., 2013), and correlation between the high $\beta$-band activity and freezing gate in PD patients (Toledo et al., 2014). Deep brain stimulation (DBS), which has been widely accepted as an effective therapeutic option of PD, is suggested to improve motor symptoms by activation of efferent fibers (Hashimoto et al., 2003), changes of oscillatory activity (Vitek, 2008) and/or decoupling STN-GPi oscillations (Moran et al., 2012). By contrast, in the course of MPTP-treatment of monkeys, the appearance of PD motor symptoms preceded that of oscillatory activity (Leblois et al., 2007), seeming to contradict the firing pattern model.

In this article, we would like to summarize our recent work on the mechanism regulating the abnormal BG oscillations (Tachibana et al., 2011) and discuss its significance in PD pathophysiology.

\section{OSCILLATORY ACTIVITY IN THE BG OF PD}

The firing properties of $\mathrm{BG}$ neurons were compared between the normal and PD states of macaque monkeys. PD states were induced by MPTP treatment $(2.4-2.5 \mathrm{mg} / \mathrm{kg}$, carotid artery injection and additional intravenous injections). The average firing rates of GPe neurons were significantly decreased (normal, 65.2 $\pm 25.8 \mathrm{~Hz}$; PD, $41.2 \pm 22.5 \mathrm{~Hz}$ ) and those of STN neurons were significantly increased (normal, $19.8 \pm 9.7 \mathrm{~Hz}$; PD, $27.6 \pm 11.4$ $\mathrm{Hz}$ ) in the PD state, whereas the firing rate of GPi neurons were not changed (normal, $67.0 \pm 24.3 \mathrm{~Hz}$; PD, $63.1 \pm 26.9 \mathrm{~Hz}$ ). These data contradict the firing rate model. Burst strength (Levy et al., 2001a; Wichmann and Soares, 2006) was increased in the $\mathrm{GPi} / \mathrm{GPe}$ and STN of the PD states. The mean power (Soares et al., 2004; Rivlin-Etzion et al., 2006) of the $8-15 \mathrm{~Hz}$ (low- $\beta$ ) oscillations was increased in the GPi/GPe and STN, whereas there were no consistent changes in the $3-8 \mathrm{~Hz}$ and $15-30 \mathrm{~Hz}$ (high$\beta$ ) oscillations. Oscillatory bursts of GPi/GPe and STN neurons were observed as multiple peaks in the autocorrelograms (e.g., Figures 1B1, 2B1, 3B1). The peak frequency with a maximum power of the oscillatory bursts of GPi/GPe and STN neurons was around $14 \mathrm{~Hz}$ (Figures 1B2, 2B2, 3B2).

\section{DA DEPENDENCE OF BG OSCILLATIONS}

We first tested whether the abnormal BG oscillations depend on DAergic inputs. DA was administrated systemically to PD monkeys, and the effects on the neuronal activity of GPi/GPe and STN neurons were examined. The motor disability was ameliorated within $5 \mathrm{~min}$ after intravenous L-DOPA injections (2.5-3.5 mg/kg, iv). L-DOPA administration decreased $8-15 \mathrm{~Hz}$ oscillations in the GPi/GPe and STN. Approximately $30 \mathrm{~min}$ after L-DOPA injections, the monkeys returned to the PD states, and the abnormal oscillations reappeared. The overall firing rate was not changed throughout the injections. These results have demonstrated that abnormal burst firing and 8-15 Hz oscillatory activity of GPi/GPe and STN neurons are DA-dependent. They also suggest that neuronal oscillations in the GPi/GPe and STN, rather than their spontaneous firing rate changes, may be critical for PD symptoms, supporting the firing pattern model.

\section{ORIGINS OF ABNORMAL GPi/GPe OSCILLATIONS}

Then, the origins of 8-15 Hz GPi/GPe oscillations were examined. The GPi (Tachibana et al., 2008) and GPe (Kita et al., 2004) receive glutamatergic inputs from the STN and GABAergic inputs from the striatum and GPe (GPe-GPe projections via the intranuclear
A

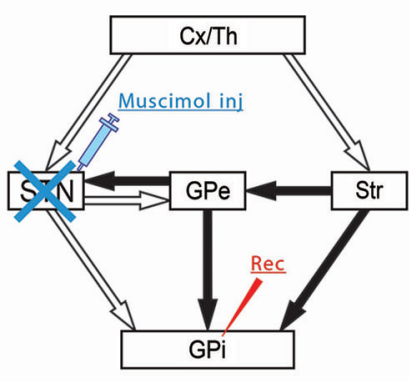

B 1

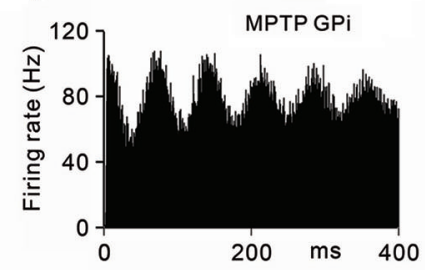

$\mathrm{C}_{1}$

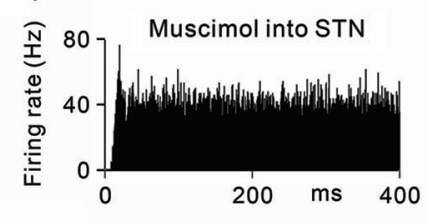

2

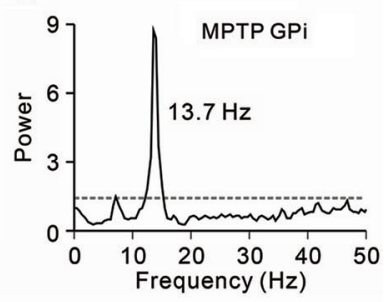

2

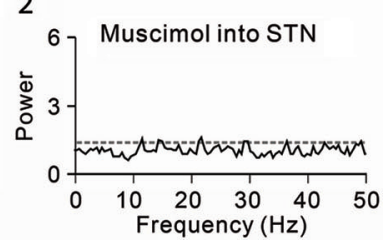

FIGURE 1 | Effects of subthalamic nucleus (STN) inactivation on neuronal activity of the internal segment of the globus pallidus (GPi) under the parkinsonian state. (A) A schematic diagram showing anatomical connections of the basal ganglia and the experimental method. Recording from GPi neurons was performed with muscimol injection into the STN to block STN inputs to the GPi. Open and filled arrows represent glutamatergic and GABAergic projections, respectively. $\mathrm{Cx}$, cerebral cortex; GPe, external segment of the globus pallidus; Str, striatum; Th, thalamus. (B) A representative GPi neuron showing abnormal oscillations in the parkinsonian state. (1) Autocorrelograms calculated from a 50-s spike train and (2) power spectra of the same spike trains are shown. Gray dashed lines represent a confidence level of $P=0.01$. (C) Muscimol inactivation of the STN decreased the firing rate and 8-15 $\mathrm{Hz}$ oscillatory activity of the GPi neuron. Modified from Tachibana et al. (2011) 
axon collaterals). To determine which inputs contribute to abnormal 8-15 Hz GPi oscillations, each input was selectively blocked. Firstly, the STN was inactivated by injection of a $\mathrm{GABA}_{\mathrm{A}}$ receptor agonist, muscimol $(4.4 \mathrm{mM}, 0.5-1.0 \mu \mathrm{L})$ while GPi neuronal activity was simultaneously recorded (Figure 1A). Inactivation of the STN ameliorated PD motor signs, such as bradykinesia and rigidity, as previously reported (Bergman et al., 1990; Wichmann et al., 1994; Levy et al., 2001b) and decreased the 8-15 Hz oscillations (Figures 1B, C) and the firing rate.

Secondly, GABAergic inputs from the striatum and GPe were blocked, and the effects on the oscillatory activity of GPi/GPe neurons were examined. Microinjection of a $\mathrm{GABA}_{\mathrm{A}}$ receptor antagonist, gabazine $(1 \mathrm{mM}, 0.1-0.2 \mu \mathrm{L})$ in the vicinity of recorded GPi/GPe neurons increased the firing rate of GPi/GPe neurons, and augmented the $8-15 \mathrm{~Hz}$ GPi oscillations, but induced no changes in GPe oscillations. These results suggest that $8-15 \mathrm{~Hz}$ GPi/GPe oscillations are generated by glutamatergic inputs mainly from the STN, but not by GABAergic inputs from the striatum and GPe.

\section{ORIGINS OF ABNORMAL STN OSCILLATIONS}

Next, the origins of $8-15 \mathrm{~Hz}$ STN oscillations were examined. The STN receives glutamatergic inputs from the cerebral cortex and the thalamus, and GABAergic inputs from the GPe. Firstly, ionotropic glutamatergic inputs were blocked, and the effects on the oscillatory activity of STN neurons were examined (Figure 2A). Microinjection $(0.1-0.2 \mu \mathrm{L})$ of a mixture of an $N$-methyl-D-aspartate receptor antagonist, 3-(2carboxypiperazin-4-yl)-propyl-1-phosphonic acid (CPP, $1 \mathrm{mM}$ ) and an AMPA/kainate receptor antagonist, 1,2,3,4-tetrahydro6-nitro-2,3-dioxo-benzo[f] quinoxaline-7-sulfonamide (NBQX, $1 \mathrm{mM})$ in the vicinity of recorded STN neurons decreased the 8-15 Hz oscillations (Figures 2B, C).
Secondly, GABAergic inputs from the GPe were blocked, and the effects on the oscillatory activity of STN neurons were examined (Figure 3A). Muscimol inactivation $(1-2 \mu \mathrm{L})$ of the GPe attenuated the $8-15 \mathrm{~Hz}$ STN oscillations (Figures 3B, C) and increased the firing rate. However, the GPe inactivation induced no clear behavioral changes. These findings have shown that the $8-15 \mathrm{~Hz}$ STN oscillation are generated by glutamatergic inputs from the cortex and thalamus and GABAergic inputs from the GPe.

Previous studies reported the coherence between the electrocorticogram and the STN LFPs/STN unit activity in the $\mathrm{PD}$ state and have suggested that cortical glutamatergic inputs can drive STN oscillations in frequency bands below $30 \mathrm{~Hz}$ (Magill et al., 2000, 2001; Sharott et al., 2005; Mallet et al., $2008 \mathrm{~b})$. It is hypothesized that cortical $\beta$-rhythm is preferentially transmitted to the BG (Brittain and Brown, 2014). This idea is also supported by an optogenetic study that selective stimulation of cortico-STN projections ameliorated PD symptoms (Gradinaru et al., 2009). The other glutamatergic inputs to the primate STN may come from the intralaminar thalamic nuclei (Lanciego et al., 2009). The parafascicular thalamic nucleus (PF) neurons in PD rats showed oscillatory activity (0.5-2.5 $\mathrm{Hz}$ ), but PF firings lagged STN firings (Parr-Brownlie et al., 2009).

Another origin of STN oscillations may be the GABAergic inputs from the GPe (Baufreton et al., 2005a). An in vivo rat study indicated that $15-30 \mathrm{~Hz}$ oscillations between GPe and STN neurons were developed during DA depletion (Mallet et al., 2008a). DAergic innervation in the GPe was decreased in PD monkeys (Schneider and Dacko, 1991), and the GPe-GPe GABAergic transmission was augmented (Watanabe et al., 2009). The oscillatory glutamatergic inputs mainly from the cortex and synchronized GABAergic inputs from the GPe may accelerate the
A

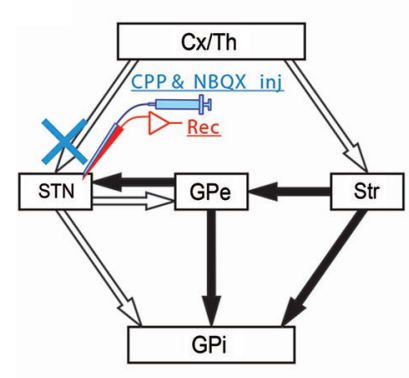

B 1

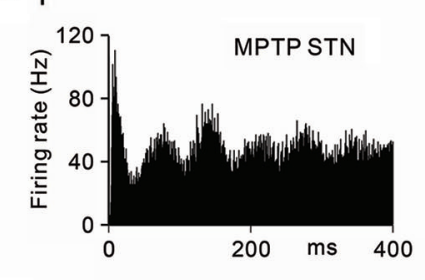

$\mathbf{C}_{1}$

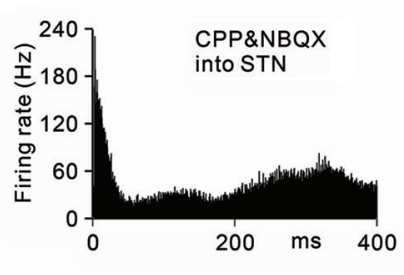

2

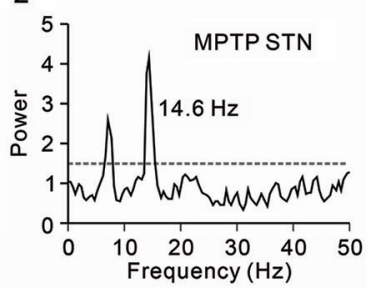

2

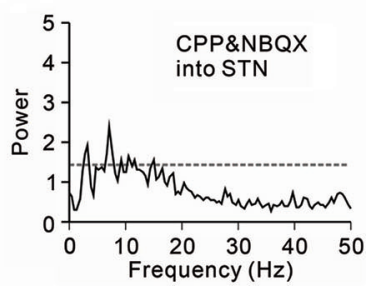

FIGURE 2 | Effects of the blockade of ionotropic glutamatergic inputs to STN neurons under the parkinsonian state. (A) Recording from STN neurons was performed with intrasubthalamic microinjection of CPP and NBQX to block glutamatergic inputs to the STN. (B) A representative STN neuron showing abnormal oscillatory activity under the parkinsonian state. (C) Intrasubthalamic microinjection of CPP and NBQX decreased 3-8 Hz and $8-15 \mathrm{~Hz}$ oscillations of the STN neuron. Modified from Tachibana et al. (2011). 
A

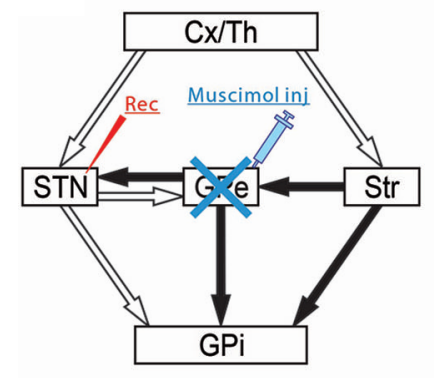

$\mathrm{B}_{1}$

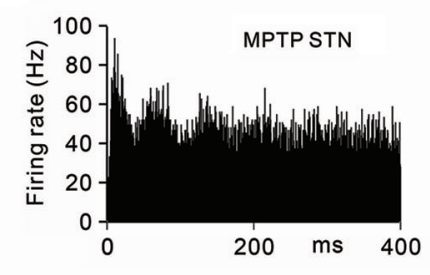

$C_{1}$

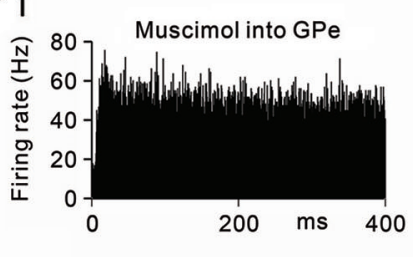

2

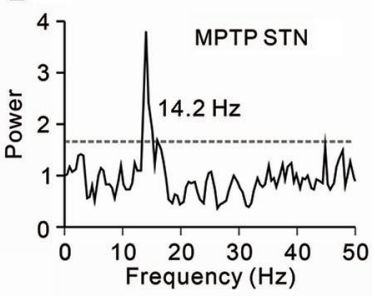

2

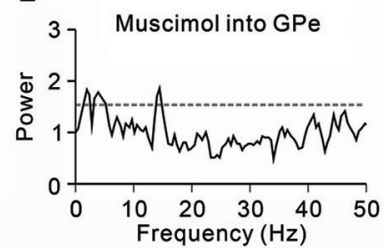

FIGURE 3 | Effects of GPe inactivation on STN neurons under the parkinsonian state. (A) Recording from STN neurons was performed with muscimol injection into the GPe to block GABAergic inputs from the GPe. (B) A representative STN neuron showing abnormal 8-15 Hz oscillations under the parkinsonian state. (C) Muscimol inactivation of the GPe decreased the 8-15 Hz oscillations and increased the firing rate of the STN neuron. Modified from Tachibana et al. (2011). oscillatory activity in STN neurons (Shen and Johnson, 2000, 2005; Baufreton et al., 2005b; Baufreton and Bevan, 2008).

\section{BG OSCILLATIONS AND PD PATHOPHYSIOLOGY}

Our work shows the following results: (1) The loss of DA induced abnormal 8-15 Hz oscillations in GPi/GPe and STN neurons; (2) The abnormal 8-15 Hz GPi/GPe and STN oscillations were reversed by systemic DA administration; (3) The abnormal 8-15 Hz GPi/GPe oscillations were originated from the STN oscillations; and (4) The STN oscillations were driven by glutamatergic inputs mainly from the cortex and GABAergic inputs from the GPe. These findings support the firing pattern model and suggest the mechanism of BG oscillations: Glutamatergic inputs to the STN and reciprocal GPe-STN interconnections generate and amplify the oscillatory activity of STN and GPe neurons in PD. Such oscillatory activity is subsequently transmitted to GPi neurons, and finally reaches the thalamus, cortex and brain stem, contributing to the expression of PD symptoms (Figure 4).

The causal relationship between the BG oscillations and PD symptoms is a fundamental question. Leblois et al. (2007) have reported that oscillatory activity of $\mathrm{BG}$ neurons does not precede the appearance of PD motor symptoms in the course of chronic MPTP treatment of monkeys, questioning such causal relationship. Moreover, acute disruption of DA transmission did not develop oscillatory activity, which is distinct from chronically depleted animals (Mallet et al., 2008b). The BG oscillations may merely reflect other fundamental activity changes. In PD, the balance between the cortico-STN-GPi hyperdirect (Nambu et al., 2000), cortico-striato-GPi direct and cortico-striato-GPe indirect pathways was lost by the lack of DA in the striatum, and the "dynamic" network properties of the BG were changed (Nambu et al., 2005; Kita and Kita, 2011). It is suggested that the imbalance between the hyperdirect and direct pathways generates the BG

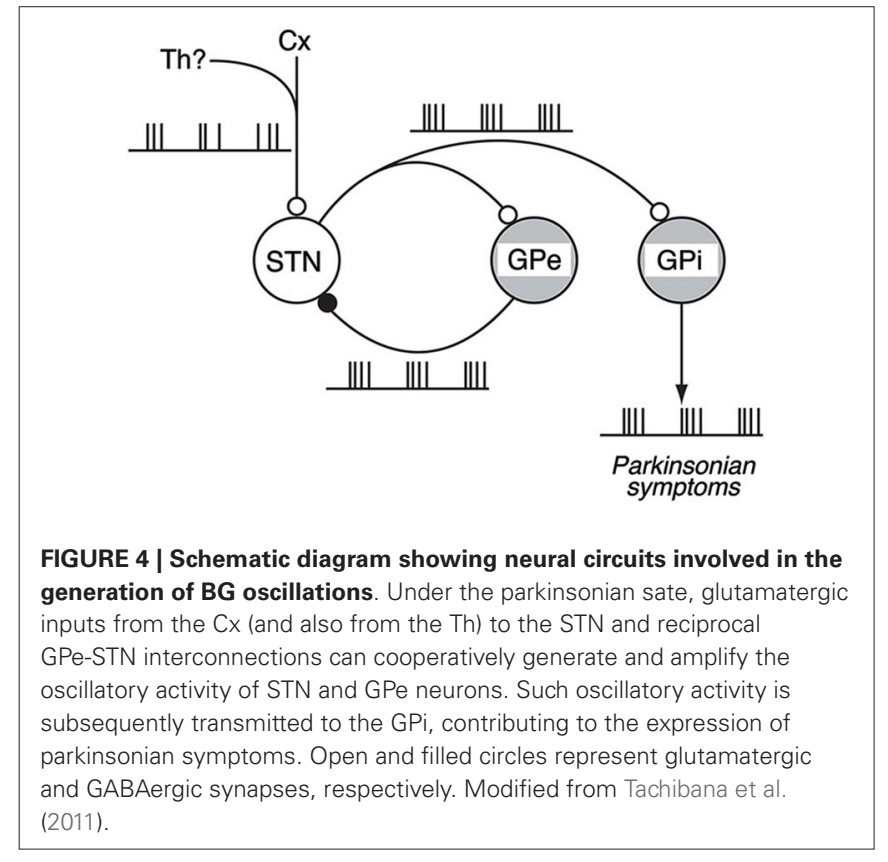

oscillations (Leblois et al., 2006). Further studies are needed to solve this fundamental question.

In this article, we would like to emphasize a close relationship between the BG oscillations and PD symptoms. In fact, DAergic medication, STN-DBS, and voluntary movements in human patients are all reported to decrease the cortico-BG synchronization (Brown et al., 2001, 2004; Cassidy et al., 2002; Levy et al., 2002; Williams et al., 2002; Silberstein et al., 2005; Lafreniere-Roula et al., 2010). In a similar manner, the suppression of $8-15 \mathrm{~Hz}$ oscillations in the primate BG may be essential to ameliorate PD motor symptoms. These findings could shed light 
on the pathophysiology of $\mathrm{PD}$ and understanding the mechanisms of current therapies, and lead us to further rational treatments of PD.

\section{REFERENCES}

Baufreton, J., Atherton, J. F., Surmeier, D. J., and Bevan, M. D. (2005a). Enhancement of excitatory synaptic integration by GABAergic inhibitionin the subthalamic nucleus. J. Neurosci. 25, 8505-8517. doi: 10.1523/jneurosci.1163-05. 2005

Baufreton, J., and Bevan, M. D. (2008). D2-like dopamine receptor-mediated modulation of activity-dependent plasticity at GABAergic synapses in the subthalamic nucleus. J. Physiol. 586, 2121-2142. doi: 10.1113/jphysiol.2008. 151118

Baufreton, J., Zhu, Z. T., Garret, M., Bioulac, B., Johnson, S. W., and Taupignon, A. I. (2005b). Dopamine receptors set the pattern of activity generated in subthalamic neurons. FASEB J. 19, 1771-1777. doi: 10.1096/fj.043401 hyp

Bergman, H., Feingold, A., Nini, A., Raz, A., Slovin, H., Abeles, M., et al. (1998). Physiological aspects of information processing in the basal ganglia of normal and parkinsonian primates. Trends Neurosci. 21, 32-38. doi: 10.1016/s01662236(97)01151-x

Bergman, H., Wichmann, T., and DeLong, M. R. (1990). Reversal of experimental parkinsonism by lesions of the subthalamic nucleus. Science 249, 1436-1438. doi: 10.1126/science. 2402638

Brittain, J. S., and Brown, P. (2014). Oscillations and the basal ganglia: Motor control and beyond. Neuroimage 85, 637-647. doi: 10.1016/j.neuroimage.2013. 05.084

Brown, P. (2007). Abnormal oscillatory synchronisation in the motor system leads to impaired movement. Curr. Opin. Neurobiol. 17, 656-664. doi: 10.1016/j.conb. 2007.12.001

Brown, P., Mazzone, P., Oliviero, A., Altibrandi, M. G., Pilato, F., Tonali, P. A., et al. (2004). Effects of stimulation of the subthalamic area on oscillatory pallidal activity in Parkinson's disease. Exp. Neurol. 188, 480-490. doi: 10.1016/j. expneurol.2004.05.009

Brown, P., Oliviero, A., Mazzone, P., Insola, A., Tonali, P., and Di Lazzaro, V. (2001). Dopamine dependency of oscillations between subthalamic nucleus and pallidum in Parkinson's disease. J. Neurosci. 21, 1033-1038.

Cassidy, M., Mazzone, P., Oliviero, A., Insola, A., Tonali, P., Di Lazzaro, V., et al. (2002). Movement-related changes in synchronization in the human basal ganglia. Brain 125, 1235-1246. doi: 10.1093/brain/awf135

DeLong, M. R. (1990). Primate models of movement disorders of basal ganglia origin. Trends Neurosci. 13, 281-285. doi: 10.1016/0166-2236(90)90110-v

Gradinaru, V., Mogri, M., Thompson, K. R., Henderson, J. M., and Deisseroth, K. (2009). Optical deconstruction of parkinsonian neural circuitry. Science 324, 354-359. doi: 10.1126/science.1167093

Hashimoto, T., Elder, C. M., Okun, M. S., Patrick, S. K., and Vitek, J. L. (2003). Stimulation of the subthalamic nucleus changes the firing pattern of pallidal neurons. J. Neurosci. 23, 1916-1923.

Kita, H., and Kita, T. (2011). Cortical stimulation evokes abnormal responses in the dopamine-depleted rat basal ganglia. J. Neurosci. 31, 10311-10322. doi: 10. 1523/JNEUROSCI.0915-11.2011

Kita, H., Nambu, A., Kaneda, K., Tachibana, Y., and Takada, M. (2004). Role of ionotropic glutamatergic and GABAergic inputs on the firing activity of neurons in the external pallidum in awake monkeys. J. Neurophysiol. 92, 3069-3084. doi: 10.1152/jn.00346.2004

Lafreniere-Roula, M., Darbin, O., Hutchison, W. D., Wichmann, T., Lozano, A. M., and Dostrovsky, J. O. (2010). Apomorphine reduces subthalamic neuronal entropy in parkinsonian patients. Exp. Neurol. 225, 455-458. doi: 10.1016/j. expneurol.2010.07.016

Lanciego, J. L., Lopez, I. P., Rico, A. J., Aymerich, M. S., Perez-Manso, M., Conte, L., et al. (2009). The search for a role of the caudal intralaminar nuclei in the pathophysiology of Parkinson's disease. Brain Res. Bull. 78, 55-59. doi: 10.1016/j. brainresbull.2008.08.008

Leblois, A., Boraud, T., Meissner, W., Bergman, H., and Hansel, D. (2006). Competition between feedback loops underlies normal and pathological dynamics in the basal ganglia. J. Neurosci. 26, 3567-3583. doi: 10.1523/jneurosci.5050-05. 2006
Leblois, A., Meissner, W., Bioulac, B., Gross, C. E., Hansel, D., and Boraud, T. (2007). Late emergence of synchronized oscillatory activity in the pallidum during progressive Parkinsonism. Eur. J. Neurosci. 26, 1701-1713. doi: 10.1111/j. 1460-9568.2007.05777.x

Levy, R., Ashby, P., Hutchison, W. D., Lang, A. E., Lozano, A. M., and Dostrovsky, J. O. (2002). Dependence of subthalamic nucleus oscillations on movement and dopamine in Parkinson's disease. Brain 125, 1196-1209. doi: 10. 1093/brain/awf128

Levy, R., Dostrovsky, J. O., Lang, A. E., Sime, E., Hutchison, W. D., and Lozano, A. M. (2001a). Effects of apomorphine on subthalamic nucleus and globus pallidus internus neurons in patients with Parkinson's disease. J. Neurophysiol. 86, 249-260.

Levy, R., Hutchison, W. D., Lozano, A. M., and Dostrovsky, J. O. (2000). Highfrequency synchronization of neuronal activity in the subthalamic nucleus of parkinsonian patients with limb tremor. J. Neurosci. 20, 7766-7775.

Levy, R., Lang, A. E., Dostrovsky, J. O., Pahapill, P., Romas, J., Saint-Cyr, J., et al. (2001b). Lidocaine and muscimol microinjections in subthalamic nucleus reverse Parkinsonian symptoms. Brain 124, 2105-2118. doi: 10.1093/brain/124. 10.2105

Magill, P. J., Bolam, J. P., and Bevan, M. D. (2000). Relationship of activity in the subthalamic nucleus-globus pallidus network to cortical electroencephalogram. J. Neurosci. 20, 820-833.

Magill, P. J., Bolam, J. P., and Bevan, M. D. (2001). Dopamine regulates the impact of the cerebral cortex on the subthalamic nucleus-globus pallidus network. Neuroscience 106, 313-330. doi: 10.1016/s0306-4522(01)00281-0

Mallet, N., Ballion, B., Le Moine, C., and Gonon, F. (2006). Cortical inputs and GABA interneurons imbalance projection neurons in the striatum of parkinsonian rats. J. Neurosci. 26, 3875-3884. doi: 10.1523/jneurosci.4439-05.2006

Mallet, N., Pogosyan, A., Marton, L. F., Bolam, J. P., Brown, P., and Magill, P. J. (2008a). Parkinsonian beta oscillations in the external globus pallidus and their relationship with subthalamic nucleus activity. J. Neurosci. 28, 14245-14258. doi: 10.1523/JNEUROSCI.4199-08.2008

Mallet, N., Pogosyan, A., Sharott, A., Csicsvari, J., Bolam, J. P., Brown, P., et al. (2008b). Disrupted dopamine transmission and the emergence of exaggerated beta oscillations in subthalamic nucleus and cerebral cortex. J. Neurosci. 28, 4795-4806. doi: 10.1523/JNEUROSCI.0123-08.2008

Moran, A., Stein, E., Tischler, H., and Bar-Gad, I. (2012). Decoupling neuronal oscillations during subthalamic nucleus stimulation in the parkinsonian primate. Neurobiol. Dis. 45, 583-590. doi: 10.1016/j.nbd.2011.09.016

Moshel, S., Shamir, R. R., Raz, A., de Noriega, F. R., Eitan, R., Bergman, H., et al. (2013). Subthalamic nucleus long-range synchronization-an independent hallmark of human Parkinson's disease. Front. Syst. Neurosci. 7:79. doi: 10. 3389/fnsys.2013.00079

Nambu, A., Tachibana, Y., Kaneda, K., Tokuno, H., and Takada, M. (2005). "Dynamic model of basal ganglia functions and Parkinson's disease," in The Basal Ganglia VIII, eds J. P. Bolam, C. A. Ingham and P. J. Magill (New York: Springer), 307-312.

Nambu, A., Tokuno, H., Hamada, I., Kita, H., Imanishi, M., Akazawa, T., et al. (2000). Excitatory cortical inputs to pallidal neurons via the subthalamic nucleus in the monkey. J. Neurophysiol. 84, 289-300.

Parr-Brownlie, L. C., Poloskey, S. L., Bergstrom, D. A., and Walters, J. R. (2009). Parafascicular thalamic nucleus activity in a rat model of Parkinson's disease. Exp. Neurol. 217, 269-281. doi: 10.1016/j.expneurol.2009.02.010

Raz, A., Vaadia, E., and Bergman, H. (2000). Firing patterns and correlations of spontaneous discharge of pallidal neurons in the normal and the tremulous 1-methyl-4-phenyl-1,2,3,6-tetrahydropyridine vervet model of parkinsonism. J. Neurosci. 20, 8559-8571.

Rivlin-Etzion, M., Marmor, O., Saban, G., Rosin, B., Haber, S. N., Vaadia, E., et al. (2008). Low-pass filter properties of basal ganglia cortical muscle loops in the normal and MPTP primate model of parkinsonism. J. Neurosci. 28, 633-649. doi: 10.1523/JNEUROSCI.3388-07.2008

Rivlin-Etzion, M., Ritov, Y., Heimer, G., Bergman, H., and Bar-Gad, I. (2006). Local shuffling of spike trains boosts the accuracy of spike train spectral analysis. $J$. Neurophysiol. 95, 3245-3256. doi: 10.1152/jn.00055.2005

Schneider, J. S., and Dacko, S. (1991). Relative sparing of the dopaminergic innervation of the globus pallidus in monkeys made hemi-parkinsonian by intracarotid MPTP infusion. Brain Res. 556, 292-296. doi: 10.1016/0006-8993 (91)90318-p 
Sharott, A., Magill, P. J., Harnack, D., Kupsch, A., Meissner, W., and Brown, P. (2005). Dopamine depletion increases the power and coherence of betaoscillations in the cerebral cortex and subthalamic nucleus of the awake rat. Eur. J. Neurosci. 21, 1413-1422. doi: 10.1111/j.1460-9568.2005. 03973.x

Shen, K. Z., and Johnson, S. W. (2000). Presynaptic dopamine D2 and muscarine M3 receptors inhibit excitatory and inhibitory transmission to rat subthalamic neurones in vitro. J. Physiol. 525(Pt. 2), 331-341. doi: 10.1111/j.14697793.2000.00331.x

Shen, K. Z., and Johnson, S. W. (2005). Dopamine depletion alters responses to glutamate and GABA in the rat subthalamic nucleus. Neuroreport 16, 171-174. doi: 10.1097/00001756-200502080-00021

Silberstein, P., Pogosyan, A., Kuhn, A. A., Hotton, G., Tisch, S., Kupsch, A., et al. (2005). Cortico-cortical coupling in Parkinson's disease and its modulation by therapy. Brain 128, 1277-1291. doi: 10.1093/brain/ awh480

Soares, J., Kliem, M. A., Betarbet, R., Greenamyre, J. T., Yamamoto, B., and Wichmann, T. (2004). Role of external pallidal segment in primate parkinsonism: comparison of the effects of 1-methyl-4-phenyl-1,2,3,6tetrahydropyridine-induced parkinsonism and lesions of the external pallidal segment. J. Neurosci. 24, 6417-6426. doi: 10.1523/jneurosci.0836-04. 2004

Tachibana, Y., Iwamuro, H., Kita, H., Takada, M., and Nambu, A. (2011). Subthalamo-pallidal interactions underlying parkinsonian neuronal oscillations in the primate basal ganglia. Eur. J. Neurosci. 34, 1470-1484. doi: 10.1111/j.14609568.2011.07865.x

Tachibana, Y., Kita, H., Chiken, S., Takada, M., and Nambu, A. (2008). Motor cortical control of internal pallidal activity through glutamatergic and GABAergic inputs in awake monkeys. Eur. J. Neurosci. 27, 238-253. doi: 10.1111/j.14609568.2007.05990.x

Toledo, J. B., López-Azcárate, J., Garcia-Garcia, D., Guridi, J., Valencia, M., Artieda, J., et al. (2014). High beta activity in the subthalamic nucleus and freezing of gait in Parkinson's disease. Neurobiol. Dis. 64, 60-65. doi: 10.1016/j.nbd.2013. 12.005

Vitek, J. L. (2008). Deep brain stimulation: how does it work? Cleve. Clin. J. Med. 75(Suppl. 2), S59-S65. doi: 10.3949/ccjm.75.Suppl_2.S59
Watanabe, K., Kita, T., and Kita, H. (2009). Presynaptic actions of D2-like receptors in the rat cortico-striato-globus pallidus disynaptic connection in vitro. $J$. Neurophysiol. 101, 665-671. doi: 10.1152/jn.90806.2008

Wichmann, T., Bergman, H., and DeLong, M. R. (1994). The primate subthalamic nucleus. III. Changes in motor behavior and neuronal activity in the internal pallidum induced by subthalamic inactivation in the MPTP model of parkinsonism. J. Neurophysiol. 72, 521-530.

Wichmann, T., Bergman, H., Starr, P. A., Subramanian, T., Watts, R. L., and DeLong, M. R. (1999). Comparison of MPTP-induced changes in spontaneous neuronal discharge in the internal pallidal segment and in the substantia nigra pars reticulata in primates. Exp. Brain Res. 125, 397-409. doi: 10. 1007/s002210050696

Wichmann, T., and Soares, J. (2006). Neuronal firing before and after burst discharges in the monkey basal ganglia is predictably patterned in the normal state and altered in parkinsonism. J. Neurophysiol. 95, 2120-2133. doi: 10. 1152/jn.01013.2005

Williams, D., Tijssen, M., Van Bruggen, G., Bosch, A., Insola, A., Di Lazzaro, V., et al. (2002). Dopamine-dependent changes in the functional connectivity between basal ganglia and cerebral cortex in humans. Brain 125, 1558-1569. doi: 10. 1093/brain/awf156

Conflict of Interest Statement: The authors declare that the research was conducted in the absence of any commercial or financial relationships that could be construed as a potential conflict of interest.

Received: 27 September 2013; accepted: 14 April 2014; published online: 23 May 2014. Citation: Nambu A and Tachibana Y (2014) Mechanism of parkinsonian neuronal oscillations in the primate basal ganglia: some considerations based on our recent work. Front. Syst. Neurosci. 8:74. doi: 10.3389/fnsys.2014.00074

This article was submitted to the journal Frontiers in Systems Neuroscience.

Copyright (c) 2014 Nambu and Tachibana. This is an open-access article distributed under the terms of the Creative Commons Attribution License (CC BY). The use, distribution or reproduction in other forums is permitted, provided the original author(s) or licensor are credited and that the original publication in this journal is cited, in accordance with accepted academic practice. No use, distribution or reproduction is permitted which does not comply with these terms. 